\title{
Micro-calorimetric sensor for vapour phase explosive detection with optimized heat
} profile

Greve, Anders; Olsen, Jesper Kenneth; Boisen, Anja; Privorotskaya, N.; King, W. P.; Senesac, L.; Thundat, $\mathrm{T}$.

Published in:

Sensors, 2009 IEEE

Link to article, DOI:

10.1109/ICSENS.2009.5398551

Publication date:

2009

Document Version

Publisher's PDF, also known as Version of record

Link back to DTU Orbit

Citation (APA):

Greve, A., Olsen, J. K., Boisen, A., Privorotskaya, N., King, W. P., Senesac, L., \& Thundat, T. (2009). Microcalorimetric sensor for vapour phase explosive detection with optimized heat profile. In Sensors, 2009 IEEE (pp. 723-726). IEEE. https://doi.org/10.1109/ICSENS.2009.5398551

\section{General rights}

Copyright and moral rights for the publications made accessible in the public portal are retained by the authors and/or other copyright owners and it is a condition of accessing publications that users recognise and abide by the legal requirements associated with these rights.

- Users may download and print one copy of any publication from the public portal for the purpose of private study or research.

- You may not further distribute the material or use it for any profit-making activity or commercial gain

- You may freely distribute the URL identifying the publication in the public portal 


\title{
Micro-Calorimetric Sensor for Vapour Phase Explosive Detection with Optimized Heat Profile
}

\author{
A. Greve, J. K. Olsen, A. Boisen \\ Department of Micro- and Nanotechnology \\ Technical University of Denmark \\ Lyngby, Denmark \\ jkol@nanotech.dtu.dk
}

\author{
N. Privorotskaya, W. P. King \\ Department of Mechanical Science and Engineering \\ University of Illinois Urbana-Champaign \\ Urbana, USA
}

\author{
L. Senesac, T. Thundat \\ Life Sciences Division \\ Oak Ridge National Laboratory \\ Oak Ridge, USA
}

\begin{abstract}
A heater design, used in a micro-calorimetric sensor, has been optimized for temperature uniformity and the sensor has been used for detection of trace amounts of explosives. In this abstract the design, characterization and functionality is described. The performance of the novel heater design is characterized by measuring the Temperature Coefficient of Resistivity (TCR) values and by mapping the temperature distribution using Raman spectroscopy. The new heater design has increased the temperature uniformity and calorimetric measurements on DNT (2,4-Dinitrotoluene) show more reproducible and better defined signals.
\end{abstract}

\section{INTRODUCTION}

Security at airports and other public places need fast screening methods to ensure public safety[1]. For this reason trace explosive detection has become a predominant research activity in recent years. The leading technology in terms of sensitivity and selectivity remains to be mass spectroscopy[2] but other types of sensors are emerging.

Selectivity of gas sensors is normally achieved by immobilizing selective receptors on the sensor surface[3]. These receptors will bind only to the desired target molecule, and the binding can be detected via for example mass changes, surface stress changes or by fluorescent labeling. However it is difficult to achieve reliable and reproducible data, and regeneration of the sensor surface in order to allow for new measurements is challenging. Using calorimetric sensing, a selective surface coating can be avoided and the surface is regenerated after each measurement. In calorimetric measurements the change in desorption and/or deflagration energy is monitored until all material on the sensor is removed.

We have previously shown that the desorption and deflagration signals can reveal unique finger prints of different explosives[4] using micro calorimetric sensors. In this abstract we present the design, fabrication and characterization of these calorimetric sensors and introduce an improved design of the heater elements.

\section{DESIGN}

Some integral parts are important for fabricating a micro calorimetric sensor. The thermal mass should be low to allow for the detection of minute temperature changes due to desorption of trace amounts of explosive. The sensor should be thermally isolated in order not to loose heat to the surroundings and should incorporate both heater elements and an element for measuring temperature changes.

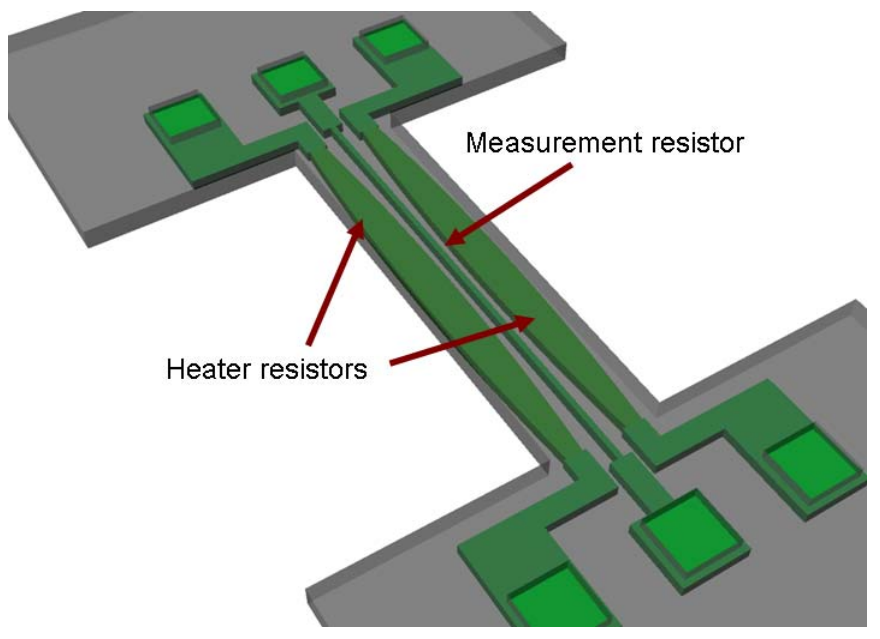

Figure 1. Illustration of the optimized resistor design. Two resistors supply heat to the bridge and a measurement resistor in the middle measures the change in the temperature of the bridge. The resistors span the whole bridge and are $400 \mu \mathrm{m}$ long. The measurement resistor is $5 \mu \mathrm{m}$ wide and the heating resistors are $32 \mu \mathrm{m}$ wide in the middle and $14 \mu \mathrm{m}$ wide at the ends. The spacing between the resistors is $10 \mu \mathrm{m}$. All resisters are $200 \mathrm{~nm}$ thick and are on the top coated with $162 \mathrm{~nm}$ silicon nitride. 
To realize these requirements a design is made incorporating two resistors for joule heating and one resistor for temperature measurements as seen in Fig. 1. The sensor is designed as a small bridge that ensures good thermal isolation. The bridge structure is made of silicon nitride with dimensions $(1 \mathrm{x}$ w x h) $400 \mu \mathrm{m} \times 100 \mu \mathrm{m} \times 400 \mathrm{~nm}$. The resistors are fabricated in doped silicon that can endure high temperatures and at the same time the large TCR value for silicon facilitates a high sensitivity of the measurement resistor. The calculated thermal mass of the bridge is approximately $30 \mathrm{~nJ} / \mathrm{K}$. Using this thermal mass desorption of $10 \mathrm{pg}$ of water corresponds to a one degree temperature change of the bridge giving an estimate of the possible sensitivity.

The goal of the optimized design is to achieve a heater shape that increases temperature uniformity over as large a part of the bridge as possible. A uniform temperature profile would ensure that phase changes of material on different locations of the bridge would happen simultaneously. This should allow for a better definition of the measured signal and maximize sensitivity and selectivity.

The heat loss of the bridge is significant at the edges due to conduction of heat to the silicon support. For this reason a lens shape heater design is used. The lens is narrow at the ends of the bridge dissipating more heat where the heat loss is greater. In the middle of the bridge the lens is widest providing less heating. The lens shaped heaters are $14 \mu \mathrm{m}$ wide at the edge of the bridge and $32 \mu \mathrm{m}$ wide in the middle of the bridge. The performance of the lens shaped heaters are compared to our first rectangular heater design with dimensions (1 x w x h) 400 $\mu \mathrm{m} \times 32 \mu \mathrm{m} \times 200 \mathrm{~nm}$.

\section{FABRICATION}

The fabrication of the micro-calorimetric sensor is illustrated in Fig. 2. A 4 inch SOI-wafer (silicon on insulator) with a device layer of $200 \mathrm{~nm}$ is boron doped by ion implantation to a resistivity of $1.54 \mathrm{~m} \Omega \mathrm{cm}$. Heating and measurement resistors are defined in the device layer by Reactive Ion Etching (RIE) using the buried silicon dioxide layer as an etch stop. Using Low Pressure Chemical Vapor deposition (LPCVD) a $162 \mathrm{~nm}$ silicon rich nitride and subsequently a 90 $\mathrm{nm}$ poly-silicon layer is deposited. The outline of the bridge and the contact holes are defined by RIE of the poly silicon, and a wet phosphoric acid etch of the silicon nitride. Next, a poly-silicon pad is defined on the middle of the bridge also using RIE. The pad is used for enhanced adsorption of explosives[5]. The bridge is finally released in a potassium hydroxide etch $(\mathrm{KOH})$ from the back side of the wafer. During $\mathrm{KOH}$ etching the front side of the wafer is protected by a Plasma Enhanced Chemical Vapor Deposition (PECVD) silicon nitride layer. The $\mathrm{KOH}$ etch is stopped on the back of the buried oxide layer. The oxide layer is then removed by $\mathrm{BHF}$ to release the bridge completely and the protective PECVD silicon nitride is removed in phosphoric acid. The electrical connections on the front side are now defined using e-beam evaporated metal (15 $\mathrm{nm} \mathrm{Ti}$ and $400 \mathrm{~nm} \mathrm{Au})$ and subsequent wet etching. a)

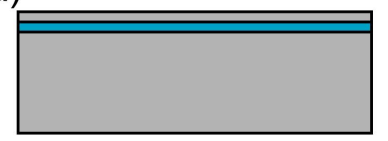

e)

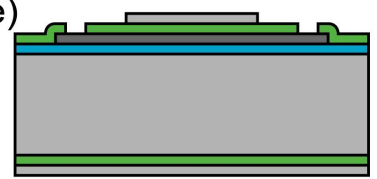

b)

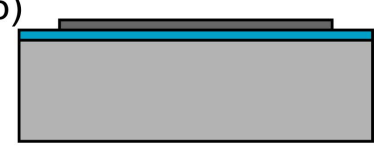

c)

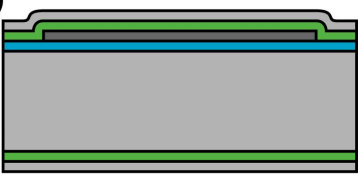

d)
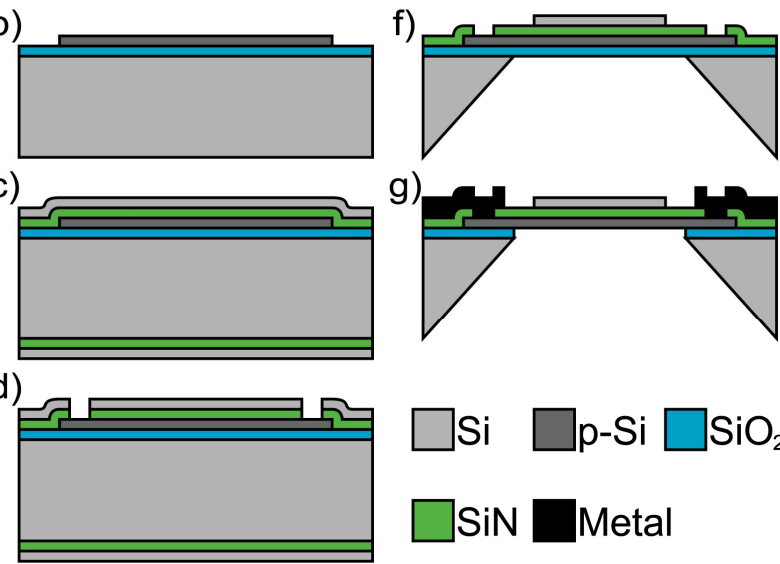

g)

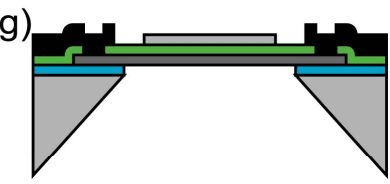

$\mathrm{Si}$

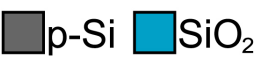

$\square \sin \square$ Metal

Figure 2. Fabrication sequence of calorimetric sensor

a) An SOI wafer with a $200 \mathrm{~nm}$ device layer is used.

b) The resisters are p-type ion implanted using boron and defined by RIE

c) Low stress silicon nitride and polysilicon are deposited on top by a LPCVD process.

d) Contact holes to resistors and outline of bridge is etched using RIE and a Phosphoric acid etch.

e) Polysilicon layer is defined using RIE

f) Bridge is defined from the back side using $\mathrm{KOH}$ etching.

g) Metal deposition and final release of bridges in hydrofluoric acid.

The wafer is diced using a diamond saw and the individual chips are mounted on PCBs and wire bonded. A SEM image of the finished sensor can be seen in Fig. 3.

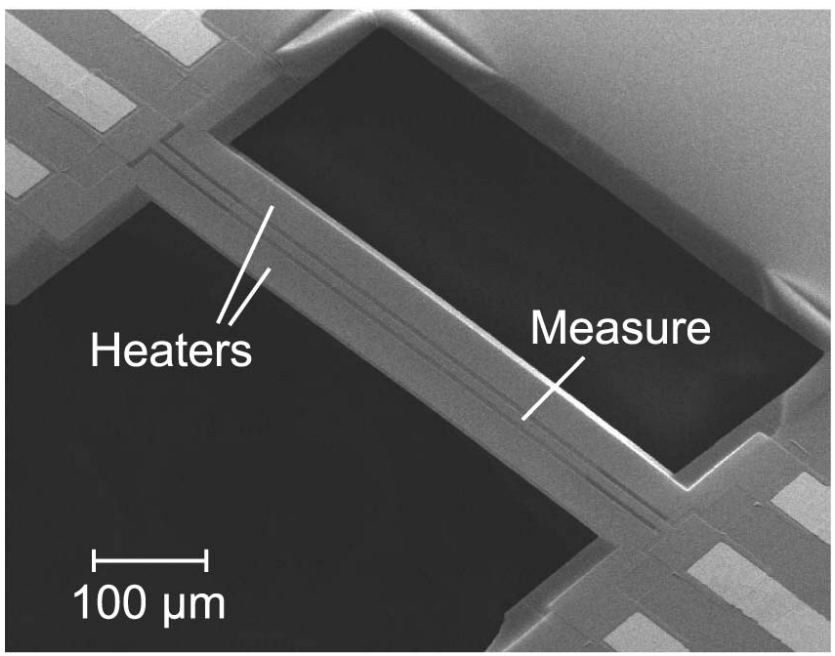

Figure 3. SEM image of a fabricated calorimetric sensor. The heating resistors and the measurement resistor can be seen under the silicon nitride layer. 


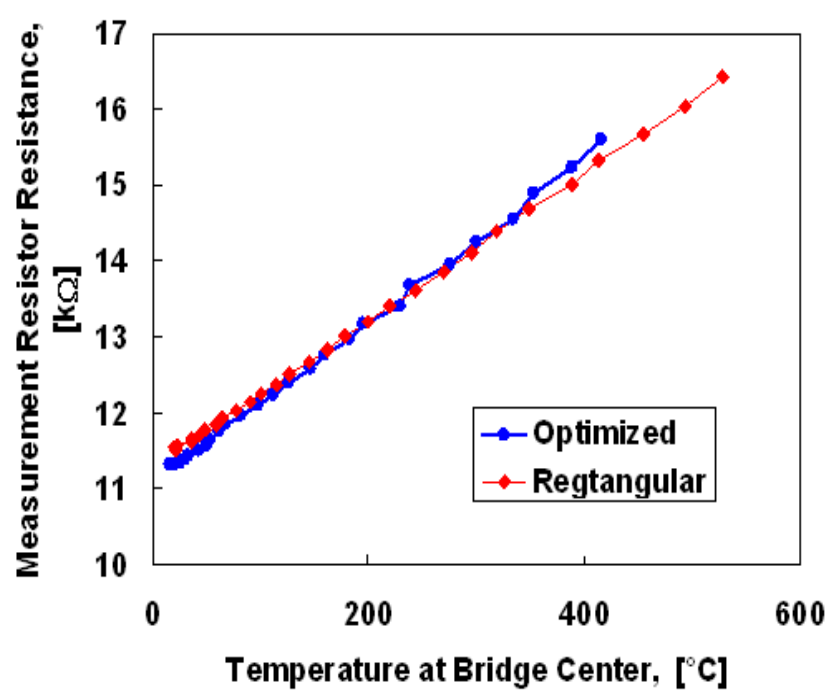

Figure 4. Raman spectroscopy temperature measurements measured at the center of an optimized bridge and on a bridge with rectangular heaters for different heater power levels. It can be seen that the resistance change is linear as a function of temperature for both designs within the measured range.

\section{CHARACTERIZATION}

To characterize the fabricated calorimetric sensor in terms of improved temperature uniformity and sensitivity, Raman spectroscopy temperature measurements have been performed. [6]

From room temperature to $500{ }^{\circ} \mathrm{C}$ the change in resistance of the highly doped silicon resistor is expected to be approximately linear. This is verified by measuring the temperature on the top of a fabricated bridge, see Fig. 4 . These measurements are done both on an optimized bridge and on a bridge with a standard rectangular heater design. Measurements are performed at the center of the bridge at different power levels. It can be seen that the slope for the optimized heater design is slightly steeper yielding higher sensitivity. By linear regression a TCR value of $0.910^{-3} /{ }^{\circ} \mathrm{K}$ can be found for the optimized design, and of $0.8510^{-3} /{ }^{\circ} \mathrm{K}$ for the rectangular heater design. This increased sensitivity is most likely due to a larger part of the bridge contributing to the resistance change. In the old design a large part of the bridge would be at a lower temperature not contributing to the change in resistance with the same magnitude.

For these measurements it should be noted that part of the resistance comes from parasitic resistances in the contact regions and at the resistor regions that are not heated.

A commercial platinum PT100 element has a TCR value of $3.910^{-3} /{ }^{\circ} \mathrm{K}$, which is approximately four times more sensitive than the calculated TCR values for the silicon resistors. When looking at the actual change in resistance per degree both the optimized and the rectangular heater design is around $10 \mathrm{Ohm} / \mathrm{K}$, where if comparing to the PT100 element the resistance change is approximately $0.4 \mathrm{Ohm} / \mathrm{K}$. The silicon resistor is inherently very sensitive

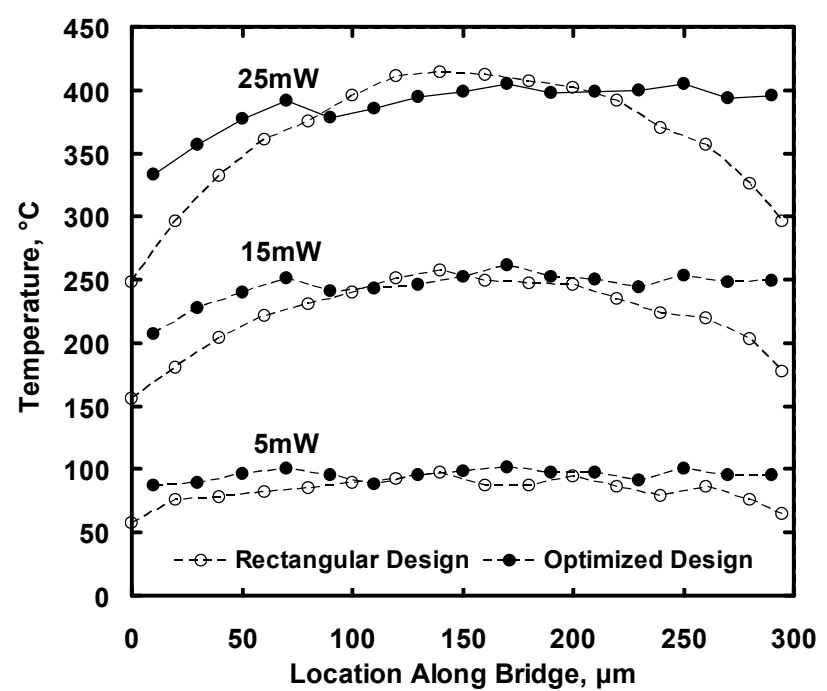

Figure 5. Raman spectroscopy temperature measurements along the length of an optimized and a standard bridge for 3 different power consumptions. Results are normalized for same power

but significant sensitivity is in the present design lost due to parasitic resistances.

A laser has been scanned along the length of the bridge, following the center axis of the measuring resistor. This has been done for both an optimized heater and a rectangular heater design at different power levels. The measurements are shown in Fig. 5. At low power levels the temperature uniformity is good for both the rectangular and the optimized heater design. As power increases the temperature distribution gets parabolic for the rectangular design. The optimized design is better at keeping a uniform temperature distribution at high powers, especially when looking at the center region.

To quantify the improvement, a measure for the non uniformity can be calculated using:

$$
\text { Nonuniformity }=\sigma\left(\frac{T(x)-T_{a v g}}{T_{a v g}}\right) \times 100 \%
$$

Here $T_{a v g}$ is average temperature and $T(x)$ is temperature measured at a given point. Measured on three different bridges with optimized and rectangular heater designs this gives an average of $12.4 \%$ nonuniformity for the standard rectangular bridges and $5.4 \%$ nonuniformity for the optimized version. This is an improvement by a factor of 2.3 .

\section{MEASUREMENTS}

The performance of the optimized heater design is compared to the performance of the original rectangular heater design in a DNT detection set-up. First, DNT dissolved in ethanol is dispensed on the chip using a micro pipette. The area of DNT crystal formation is comparable to the bridge area. The DNT crystals are randomly dispersed on the chip 
and the location of the individual crystals on the bridge differs from measurement to measurement.
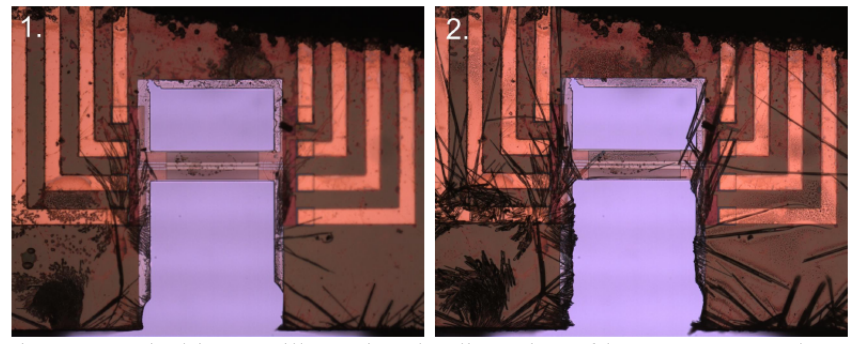

Figure 6 Optical images illustrating the dispersion of large DNT crystals on the sensor surface. Picture 1. illustrates a clean bridge after a few measurements. Picture 2. illustrates the position of DNT crystals on the bridge surface after deposition.

This is illustrated in Fig. 6. where a dispersion of crystals can be seen. A few crystals are lying at the edge of the bridge and a single small crystal is lying near the center.

Calorimetric measurements are done by applying a $20 \mathrm{~Hz}$ ramp of $10 \mathrm{~V}$ to the heater elements, heating the bridge to approximately $500{ }^{\circ} \mathrm{C}$. The measurement resistor is connected in a Wheatstone bridge configuration with a reference chip, and the output signal is amplified and recorded. Two measurements are always recorded with a small time difference and the second measurement is subtracted from the first to subtract the baseline.

In Fig. 7 four measurements of DNT on an optimized and a rectangular design are shown. The measurements on the optimized design are clearly more repeatable. The measurements with the rectangular heaters are poorly defined with multiple peaks and different peak locations. With the optimized design we believe that the DNT desorption temperature is achieved at the same time on different locations of the bridge, not changing the signal depending on the DNT crystal location. This is not the case with the rectangular heaters, where the DNT location has a large influence on the achieved signal.

We have previously [4-5] used a standard bridge design to measure very distinct thermal response curves for three different explosives. Due to the better signal definition, selectivity should improve with the new heater design.

\section{CONCLUSION}

A micro calorimetric sensor with an improved heater design has been fabricated, characterized and used for DNT measurements. Characterization has been done using Raman spectroscopy temperature measurements both to investigate sensitivity and temperature distribution. It was found that a lens shaped heater has a slightly higher sensitivity of $0.910^{-}$ ${ }^{3} /{ }^{\circ} \mathrm{K}$ compared to $0.8510^{-3} /{ }^{\circ} \mathrm{K}$ for the rectangular heater design. Temperature nonuniformity was improved from $12.4 \%$ to $5.4 \%$ when scanning across the length of the bridge. Calorimetric measurements of DNT were performed showing a much more reproducible and better defined signal when using the optimized heater design compared to the rectangular heater design.
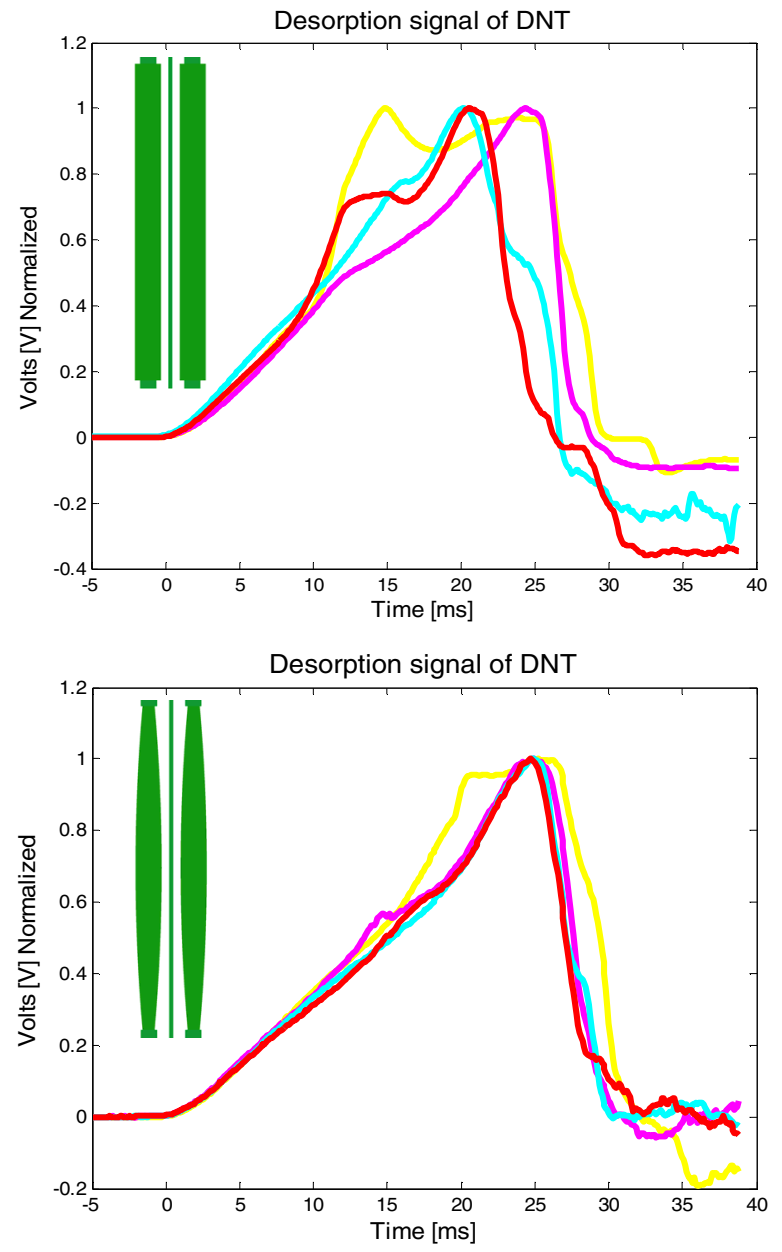

Figure 7 Four calorimetric measurements of DNT on a bridge with rectangular heaters (top) and on a bridge with optimized heaters.(bottom). Heater shape is shown in the respective graph.

\section{REFERENCES}

[1] J. P. Fitch, E. Raber and D. R. Imbro, "Technology challenges in responding to biological or chemical attacks in the civilian sector." Science (New York, N.Y.), vol. 302, pp. 1350-1354, 2003.

[2] D. S. Moore, "Recent Advances in Trace Explosives Detection Instrumentation," Sensing and Imaging: An International Journal, vol. 8, pp. 9-38, 2007.

[3] L. A. Pinnaduwage, T. Thundat, J. E. Hawk, D. L. Hedden, P. F. Britt, E. J. Houser, S. Stepnowski, R. A. McGill and D. Bubb, "Detection of 2,4-dinitrotoluene using microcantilever sensors," Sensors Actuators B: Chem., vol. 99, pp. 223-229, 2004.

[4] L. R. Senesac, Dechang Yi, A. Greve, J. H. Hales, Z. J. Davis, D. M. Nicholson, A. Boisen and T. Thundat, "Micro-differential thermal analysis detection of adsorbed explosive molecules using microfabricated bridges," Rev. Sci. Instrum., vol. 80, pp. 035102 (9 pp.), 2009.

[5] Dechang Yi, A. Greve, J. H. Hales, L. R. Senesac, Z. J. Davis, D. M. Nicholson, A. Boisen and T. Thundat, "Detection of adsorbed explosive molecules using thermal response of suspended microfabricated bridges," Appl. Phys. Lett., vol. 93, pp. 154102 (3 pp.), 2008.

[6] Jungchul Lee, T. Beechem, T. L. Wright, B. A. Nelson, S. Graham and W. P. King, "Electrical, Thermal, and Mechanical Characterization of Silicon Microcantilever Heaters," J Microelectromech Syst, vol. 15, pp. 1644-1655, 2006. 